\title{
REVIEW
}

\section{Nevus Comedonicus: An Updated Review}

Georgi Tchernev $\cdot$ Julian Ananiev $\cdot$ Kristina Semkova $\cdot$

Lyubomir A. Dourmishev $\cdot$ Jaqueline Schönlebe $\cdot$ Uwe Wollina

To view enhanced content go to www.dermtherapy-open.com

Received: April 14, 2013 / Published online: May 25, 2013

(c) The Author(s) 2013. This article is published with open access at Springerlink.com

\section{ABSTRACT}

The intention of this review on nevus comedonicus (NC) is to update on clinical features, pathogenesis, and therapy. $\mathrm{NC}$ is a rare epidermal nevus type. It is part of the nevus comedonicus syndrome, a neurocutaneous disorder with ocular, skeletal, and central nervous symptoms. Recently, acne-related signaling pathways and somatic mutations of

G. Tchernev

Policlinic for Dermatology and Venerology, Saint Kliment Ohridski University, University Hospital Lozenetz, Sofia, Bulgaria

J. Ananiev

Department General and Clinical Pathology, Medical Faculty, Trakia University, Stara Zagora, Bulgaria

K. Semkova $\cdot$ L. A. Dourmishev

Department of Dermatology and Venereology, Medical University Sofia, Sofia, Bulgaria tyrosine kinase receptors have been identified and may play a role in NC pathogenesis. On preexistent NC secondary skin tumors can develop, which are often benign. Treatment options of NC include topical therapy, laser, and surgery.

Keywords: Adnexal tumors of skin; Epidermal nevus syndrome; Nevus comedonicus; Rare skin disorders; Tyrosine kinase receptors

\author{
J. Schönlebe \\ Institute of Pathology "Georg Schmorl", Academic \\ Teaching Hospital Dresden, Friedrichstadt, \\ Friedrichstrasse 41, Dresden, Germany \\ U. Wollina $(\square)$ \\ Department of Dermatology and Allergology, \\ Academic Teaching Hospital Dresden, \\ Friedrichstadt, Friedrichstrasse 41, 01067 Dresden, \\ Germany \\ e-mail: wollina-uw@khdf.de
}




\section{INTRODUCTION}

Nevus comedonicus (NC) is a rare skin disorder. In this review, we will provide an update on clinical features, pathogenesis, and treatment options.

Clinically NC is characterized by closely arranged, dilated follicular openings with keratinous plugs resembling classical comedones. It is a rare type of an epidermal nevus usually with predilection for the face and neck area [1]. The disease was first described in 1895 by Kofmann [2] who suggested the term 'comedo nevus'.

NC can occur congenitally or develop later in life, most commonly at the age of approximately 10 years. NC is part of the nevus comedonicus syndrome (NCS), a term coined by Engber in 1978 [1, 3].

\section{Epidemiology}

The prevalence of NC has been estimated from 1 in 45,000 to 1 in 100,000 , with no gender or racial preference $[1,3]$. In $50 \%$ of patients, the condition develops shortly after birth and in the majority of patients lesions appear before the age of 10 [4-6]. Single cases of delayed development of NC and NCS at later age have been reported [4-6].

\section{Clinical Characteristics}

NC is usually asymptomatic and most commonly it affects the face and neck area and, by exception, other anatomical regions, including genital area, palms, and soles. Clinically, NC presents with grouped, dilated, plugged follicular ostia in a honeycomb pattern. The plugged ostia contain lamellated keratinaceous material. Their appearance resembles black dots but the material cannot

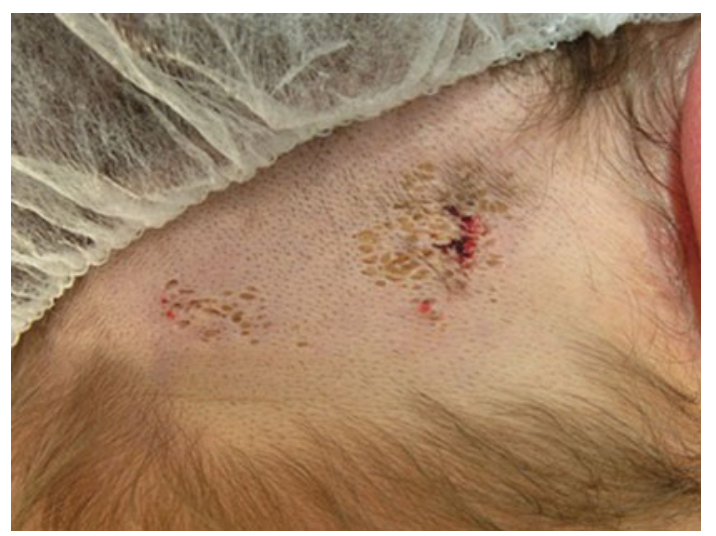

Fig. 1 Nevus comedonicus: plaque-like lesion with wide open follicles on the neck (44-year-old Caucasian male)

be easily removed mechanically in contrast to acne comedones [1, 7].

NC lesions might present with various patterns of distribution: unilateral, bilateral, linear, interrupted, segmental, or blaschkoid (Figs. 1, 2 and 3) [3].

Two types of NC have been identified; the first is non-pyogenic NC with acne-like characteristics and a second type characterized by formation of cysts, papules, pustules, and abscesses in various stages of development $[8,9]$. The former type is also known as Munro's acne nevus and separated by some authors from NC [3]. Differential diagnoses are shown in Table 1.

\section{Histopathology}

The major histopathologic symptoms are large grouped, dilated follicular ostia devoid of hair shafts but filled with keratin layers (Fig. 4). At some locations in the bases of the follicular invaginations one may observe singular rudimentary glands, which are not, however, obligatory as they may be absent. Small cysts, cystic invaginations, and occasionally large cysts may be seen in histopathologic investigation; the variable cystic structures 

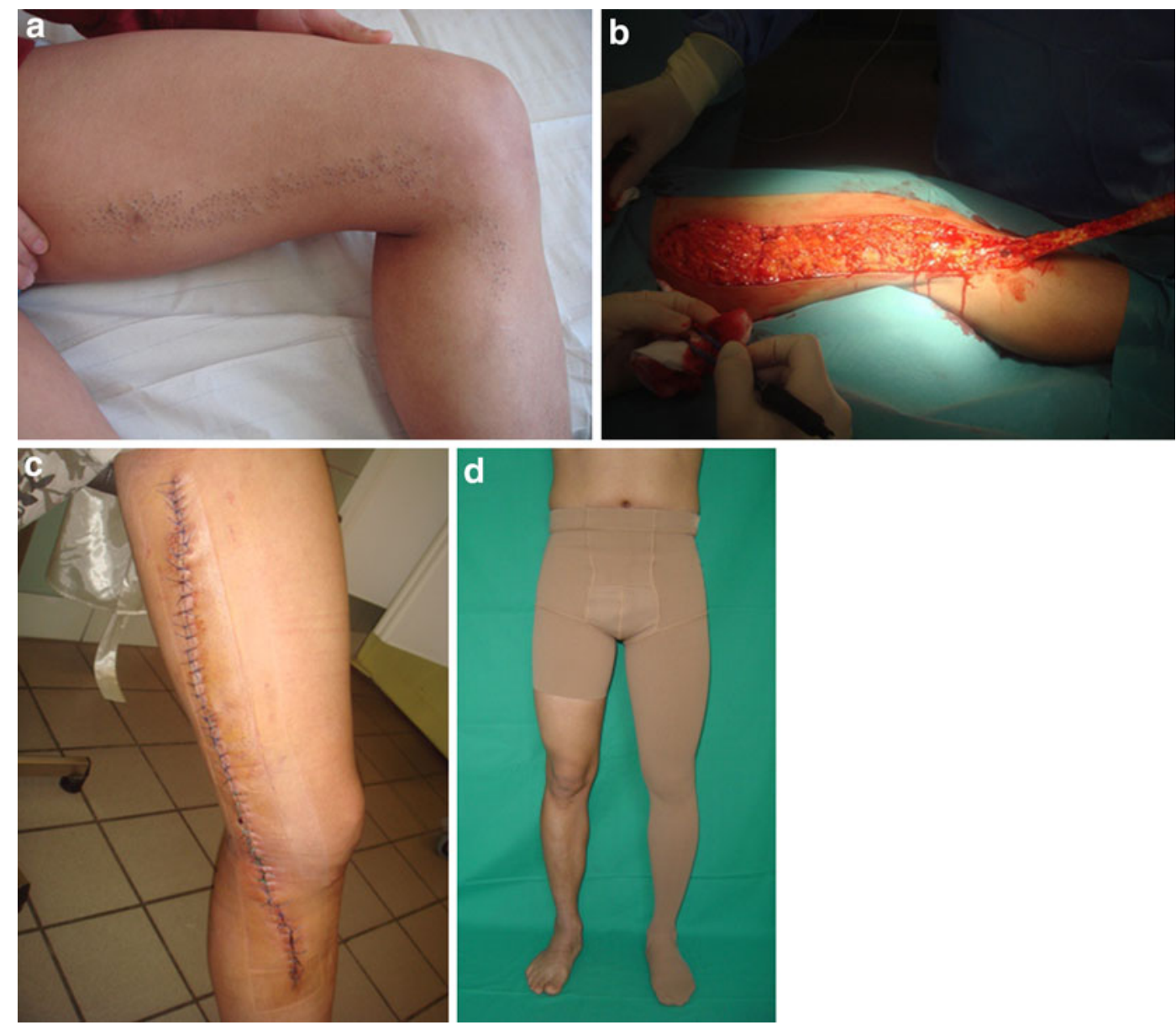

Fig. 2 Stages of treatment of a 29-year-old Asian male with weeks after surgical excision. d With compression garment linear nevus comedonicus of the leg with multiple follicular openings. a Presentation of linear nevus comedonicus with to avoid postsurgical lymphedema multiple follicular openings. b Surgical excision. c Three

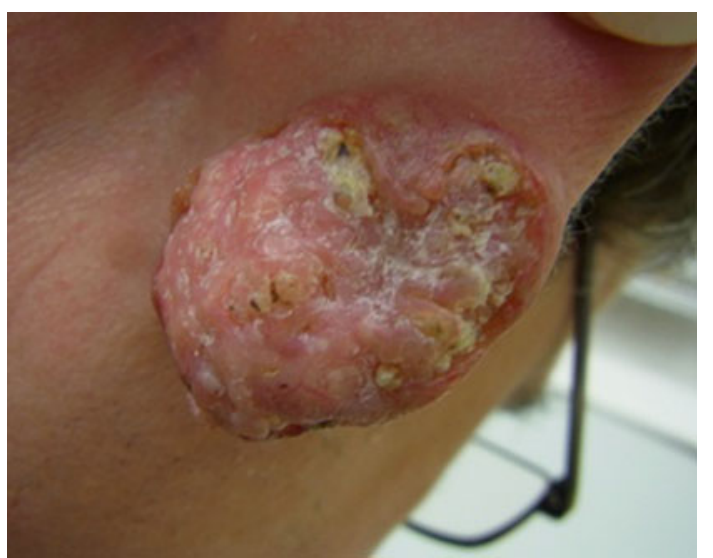

Fig. 3 Nevus comedonicus of the neck with pseudoepithelial epidermal hyperplasia in a 39-year-old Caucasian are lined by keratinizing squamous epithelium [1, 7]. Hyperkeratosis (epidermolytic hyperkeratosis) and acanthosis of the epidermis may be present but not para- or dyskeratosis [8, 10-13].

An increased number of Langerhans cells had been observed by electron microscopy [11]. More abundant tonofilaments in the upper part of the stratum spinosum and numerous keratohyalin granules were also noticed $[11,12]$. The arrector pili muscles were incompletely differentiated and demonstrated intracellular glycogen particles $[11,12]$. 


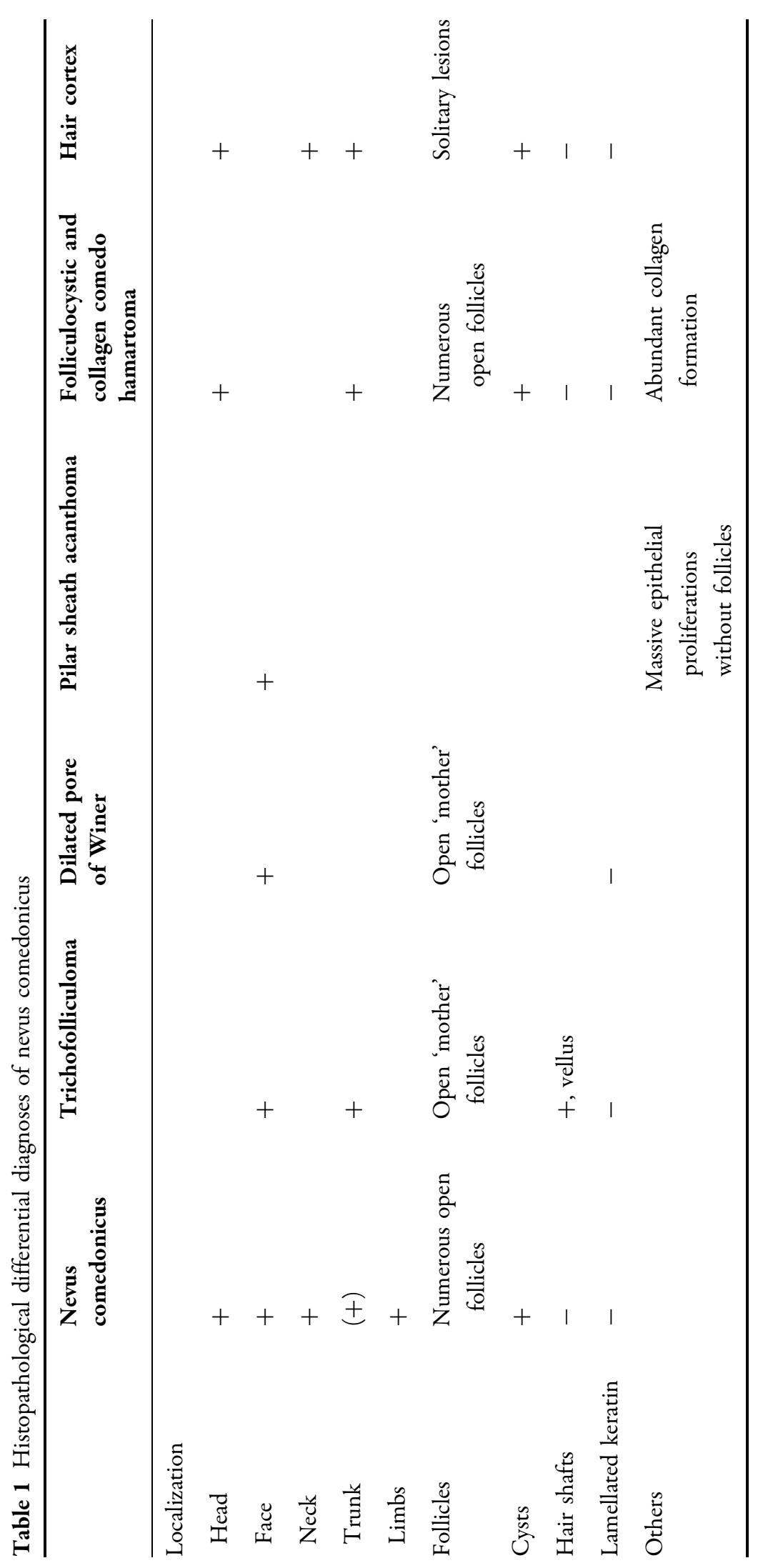



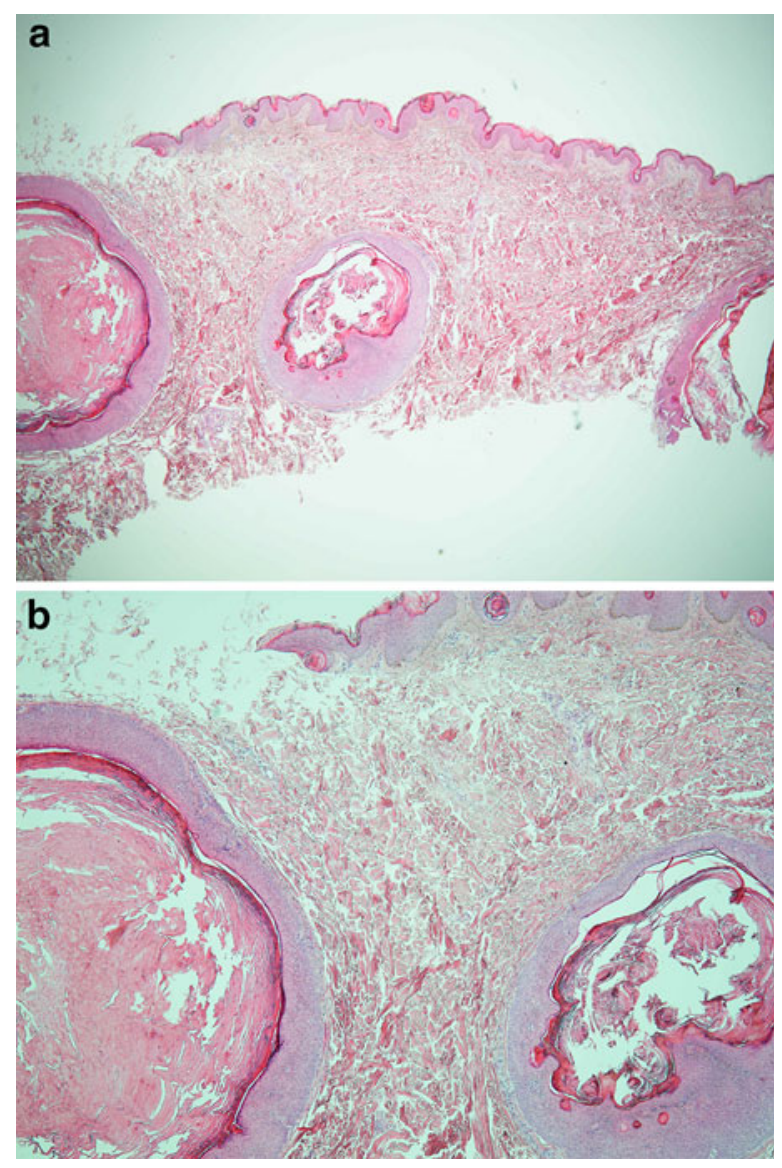

Fig. 4 Histopathology of nevus comedonicus. a Overview (hematoxylin and eosin stain $[\mathrm{HE}] \times 2$ ). b Details with large follicles containing lamellated keratin but absent hair shafts $(\mathrm{HE} \times 4)$

Cytokeratin expression in NC is comparable to that in normal skin [14]. Filaggrin, which is usually located in the granular epidermal layer, occurs in the whole epidermis of closed comedones suggesting its role in their development [14, 15].

Interaction between fibroblast growth factor (FGF) and FGF receptor-2 (FGFR2) is a crucial pathway for mesenchymal-epithelial interplay in pilosebaceous unit development. FGFR is a family of tyrosine kinase receptors. FGFR2b is exclusively found in epithelial cells including epidermal keratinocytes and sebocytes $[15,16]$. Overstimulation of FGFR2 signaling with increased expression of interleukin- $1 \alpha$ may be involved in NC pathogenesis. Somatic mutations like Ser252Trp substation have been identified in individual patients with segmental acne [16-18].

$\gamma$-Secretase found in human hair follicle epithelium is another candidate for NC since the absence of this enzyme results in complete conversion of hair follicles to epidermal cysts [19].

\section{Association with Genetic Syndromes and Other Diseases}

NCS (ORPHA64754) belongs to the group of epidermal nevus syndromes including Schimmelpenning syndrome, phacomatosis pigmentokeratotica, angora hair nevus syndrome, and Becker nevus syndrome among others where a genetic basis has yet not been identified [3, 4, 20].

NCS is a neurocutaneous disorder which consists of NC with skeletal, ocular, and central nervous system abnormalities. The most common symptoms include cataracts, scoliosis, fused vertebrae, spina bifida, and delayed mental development $[5,6]$. In addition, seizures, paresis, dysgenesis of corpus callosum, electroencephalographic abnormalities, limb deformities such as absence of the fifth finger, polysyndactyly or clinodactyly, oligodontia, and other skin disorders such as ichthyosis, leukoderma, lichen striatus, linear morphea, Sturge-Weber syndrome, hemangiomas, and inverse acne have been reported in NCS [1, 3, 4, 20-22].

NCS is associated with epithelial tumors such as trichoepithelioma, pilar sheath tumor or dilated pore of Winer, keratoacanthoma, syringocystadenoma papilliferum, hidradenoma papilliferum, and very rarely basal cell carcinoma or squamous cell carcinoma [23-26]. 


\section{TREATMENT}

Being benign, NC does not require aggressive treatment, except for aesthetic reasons or in complicated cases. Conservative options include emollients and moisturizer, topical corticosteroids (for inflammatory lesions), keratolytics such as salicylic acid, or $12 \%$ ammonium lactate solution. Conservative treatment may improve cosmesis in some patients $[27,28]$.

Since retinoids are working in acne, they have also been used in NC. Achievements with topical tretinoin are limited. Some reports showed better improvement of NC by topical tazarotene as monotherapy or in combination with topical mometasone furoate or calcipotriene [29-31]. No complete resolution can be achieved by this and relapses are common.

Oral retinoids, such as isotretinoin, were found to be ineffective in most cases but may be an option in widespread systematized inflammatory variants [32, 33]. There have, as yet, been no published studies of other retinoids, such as topical adapalene and systemic or topical bexarotene.

Of potential interest are FGFR inhibitors with antivascular activity [34]. Interleukin-1 $\alpha$ inhibitors can be classified into receptor inhibitors, such as anakinra, and monoclonal antibodies against the interleukin itself [35]. Currently, there are no data available for NC.

Another interesting drug target is $\gamma$-secretase; stimulators of this enzyme such as general control nonderepressible 2 (GCN2) - a subunit of eukaryotic translation factor 2 kinase-might be a future therapeutic option [36].

Localized NC can be removed by surgical excision with good aesthetic results in contrast to superficial shaving, comedo extraction, and dermabrasion techniques (Fig. 2a-d) [37]. If linear $\mathrm{NC}$ is surgically removed on the limbs, complex decongestive therapy including manual lymph drainage and compression garments supports the healing process (Fig. 2d). Larger lesions may need transplantation for defect closure, or another option is the use of repeat-filling or self-filling osmotic tissue expanders to obtain a resurplus of skin for defect closure [38, 39].

Laser treatments with 2,940-nm erbium YAG, 10,600-nm ultrapulsed $\mathrm{CO}_{2}$, or 1,450-nm diode lasers have shown improvement in single patients [40-42]. Skin depression will however stay. Erbium YAG laser treatment is often followed by delayed relapses. In contrast to ablative lasers, the $1,450 \mathrm{~nm}$ diode shrinks sebaceous glands and reduces seborrhea. The combination of 1,450-nm diode laser with 1,550-nm erbium-doped fiber laser has potential for treating NC [43].

\section{CONCLUSION}

With this review we provided an update on clinical features, pathogenesis and treatment option of NC. NC is a rare epidermal nevus. Diagnosis is based on clinical examination and histopathology. New data are available on signaling pathways in acne-related disorders that may have an impact on $\mathrm{NC}$ as well. In contrast to the acne-related comedones, the epithelium is often hyperkeratotic and sometimes acanthotic and comedo extraction is not as easily achieved as with acne comedones. Dermatologists should be aware of potential association of NC with skin tumors and extracutaneous findings such as NCS. The most effective treatment available is complete surgical excision. New developments in laser technology may become an alternative in near future. With a more detailed understanding in molecular pathogenesis, targeted therapy will become a future perspective. 


\section{ACKNOWLEDGMENTS}

No funding or sponsorship was received for this study or publication of this article.

Conflict of interest. Dr G. Tchernev, Dr J. Ananiev, Dr K. Semkova, Dr L.A. Dourmishev, Dr J. Schönlebe, and Dr. U. Wollina declare no conflicts of interest. Dr U. Wollina is the guarantor for this article, takes responsibility for the integrity of the work as a whole.

Open Access. This article is distributed under the terms of the Creative Commons Attribution Noncommercial License which permits any noncommercial use, distribution, and reproduction in any medium, provided the original author(s) and the source are credited.

\section{REFERENCES}

1. Nabai H, Mehregan AH. Nevus comedonicus. Acta Derm Venereol. 1973;53:71-4.

2. Kofmann S. Ein Fall von seltener Lokalisation und Verbreitung von Komedonen. Arch Dermatol Syphilol (Berlin). 1895;32:177-8.

3. Happle R. The group of epidermal nevus syndromes Part I. Well defined phenotypes. J Am Acad Dermatol. 2010;63:1-22.

4. Engber PB. The nevus comedonicus syndrome: a case report with emphasis on associated internal manifestations. Int J Dermatol. 1978;17:745-9.

5. Patrizi A, Neri I, Fiorentini C, Marzaduri S. Nevus comedonicus syndrome: a new pediatric case. Pediatr Dermatol. 1998;15:304-6.

6. Pavithra S, Pai H, Mallya H, Pai GS. Nevus comedonicus syndrome. Indian J Dermatol. 2011;56:771-2.

7. Jeong HS, Lee HK, Lee SH, et al. Multiple large cysts arising from nevus comedonicus. Arch Plast Surg. 2012;39:63-6.

8. Beck MH, Dave VK. Extensive nevus comedonicus. Arch Dermatol. 1980;116:1048-50.
9. Kim YJ, Hong CY, Lee JR. Nevus comedonicus with multiple cysts. J Korean Cleft Palate Craniofac Assoc. 2009;10:135-7.

10. Barsky S, Doyle JA, Winkelmann RK. Nevus comedonicus with epidermolytic hyperkeratosis. A report of four cases. Arch Dermatol. 1981;117: 86-8.

11. Lee $S$, Nasemann $T$, Neufahrt A. Ein Beitrag zur Histogenese des Naevus comedonicus: Histochemische, licht- und elektronenmikroskopische Untersuchungen. Hautarzt. 1972;23:534-40.

12. Cho SB, Oh SH, Lee JH, Bang D. Ultrastructural features of nevus comedonicus. Int J Dermatol. 2012;51:626-7.

13. Fritsch P, Wittels W. Ein Fall von bilateralem Naevus comedonicus. Hautarzt. 1971;22:409-12.

14. Kurokawa I, Nakai Y, Nishimura $\mathrm{K}$, et al. Cytokeratin and filaggrin expression in nevus comedonicus. J Cutan Pathol. 2007;34:338-41.

15. Wollina U. Histochemistry of the human hair follicle. EXS. 1997;78:31-58.

16. Melnik B, Schmitz G. FGFR2 signaling and the pathogenesis of acne. J Dtsch Dermatol Ges. 2008;6:721-8.

17. Munro CS, Wilkie AOM. Epidermal mosaicism producing localized acne: somatic mutation in FGFR2. Lancet. 1998;352:704-5.

18. Melnik B, Vakilzadeh F, Aslanidis C, Schmitz G. Unilateral segmental acneiform nevus-a model disorder towards understanding FGFR2 function in acne. Br J Dermatol. 2008;158:1397-9.

19. Pan $Y$, Lin MH, Tian X, et al. Gamma-secretase functions through Notch signaling to maintain skin appendages but is not required for their patterning or initial morphogenesis. Dev Cell. 2004;7:731-43.

20. Vidaurri-de la Cruz H, Tamayo-Sánchez L, DuránMcKinster C, et al. Epidermal nevus syndromes: clinical findings in 35 patients. Pediatr Dermatol. 2004;21:432-9.

21. Sinha A, Natarajan S. Linear morphea, nevus comedonicus, and lichen striatus in a 5-year-old girl. Pediatr Dermatol. 2011;28:72-4.

22. Dufour DN, Bryld LE, Jemec GB. Hidradenitis suppurativa complicating naevus comedonicus: the possible influence of mechanical stress on the development of hidradenitis suppurativa. Dermatology. 2010;220:323-5. 
23. Lee HJ, Chun EY, Kim YC, Lee MG. Nevus comedonicus with hidradenoma papilliferum and syringocystadenoma papilliferum in the female genital area. Int J Dermatol. 2002;41:933-6.

24. Zarkik S, Bouhllab J, Methgal A, et al. Keratoacanthoma arising in nevus comedonicus. Dermatol Online J. 2012;18:4.

25. Alpsoy E, Durusoy C, Ozbilim G, et al. Nevus comedonicus syndrome: a case associated with multiple basal cell carcinomas and a rudimentary toe. Int J Dermatol. 2005;44:499-501.

26. Walling HW, Swick BL. Squamous cell carcinoma arising in nevus comedonicus. Dermatol Surg. 2009;35:144-6.

27. Milton GP, Di Giovanna JJ, Peck GL. Treatment of nevus comedonicus with ammonium lactate lotion. J Am Acad Dermatol. 1989;20:324-8.

28. Bordel MT, Miranda A. Unilateral nevus comedonicus: efficacy after treatment with $12 \%$ ammonium lactate. Actas Dermosifiliogr. 2006;97:150.

29. Wakahara M, Kiyohara T, Kumakiri M, et al. Bilateral nevus comedonicus: efficacy of topical tacalcitol ointment. Acta Derm Venereol. 2003;83:51.

30. Manola I, Ljubojević S, Lipozencić J, Pustisek N. Nevus comedonicus-case report and review of therapeutical approach. Acta Dermatovenerol Croat. 2003;11:221-4.

31. Deliduka SB, Kwong PC. Treatment of nevus comedonicus with topical tazarotene and calcipotriene. J Drugs Dermatol. 2004;3:674-6.

32. Decherd JW, Mills O, Leyden JJ. Naevus comedonicus-treatment with retinoic acid. Br J Dermatol. 1972;86:528-9.

33. Peck GL, Yoder FW. Treatment of lamellar ichthyosis and other keratinizing dermatoses with an oral synthetic retinoid. Lancet. 1976;2:1172-4.
34. Dinarello CA, Simon A, van der Meer JW. Treating inflammation by blocking interleukin-1 in a broad spectrum of diseases. Nat Rev Drug Discov. 2012;11:633-52.

35. Liang G, Liu Z, Wu J, et al. Anticancer molecules targeting fibroblast growth factor receptors. Trends Pharmacol Sci. 2012;33:531-41.

36. Ohta K, Mizuno A, Ueda M, et al. Autophagy impairment stimulates PS1 expression and gamma-secretase activity. Autophagy. 2010;6:345-52.

37. Milburn S, Whallett E, Hancock K, et al. The treatment of naevus comedonicus. J Plast Surg. 2004;57:805-6.

38. Marcus J, Esterly NB, Bauer BS. Tissue expansion in a patient with extensive nevus comedonicus. Ann Plast Surg. 1992;29:362-6.

39. Wollina U, Bayyoud Y. Reconstruction of a large scalp defect by the sequential use of dermal substitute, self-filling osmotic tissue expander and rotational flap. J Cutan Aesthet Surg. 2010;3: 106-10.

40. Caers SJ, Van der Geer S, Beverdam EG, Krekels GA, Ostertag JU. Successful treatment of nevus comedonicus with the use of the erbium Yag laser. J Eur Acad Dermatol Venereol. 2008;22:375-7.

41. Sardana K, Garg VK. Successful treatment of nevus comedonicus with ultrapulse CO2 laser. Indian J Dermatol Venereol Leprol. 2009;75:534-5.

42. Givan J, Hurley MY, Glaser DA. Nevus comedonicus: a novel approach to treatment. Dermatol Surg. 2010;36:721-5.

43. Moody MN, Landau JM, Goldberg LH, Friedman PM. 1,450-nm diode laser in combination with the 1550-nm fractionated erbium-doped fiber laser for the treatment of steatocystoma multiplex: a case report. Dermatol Surg. 2012;38:1104-6. 